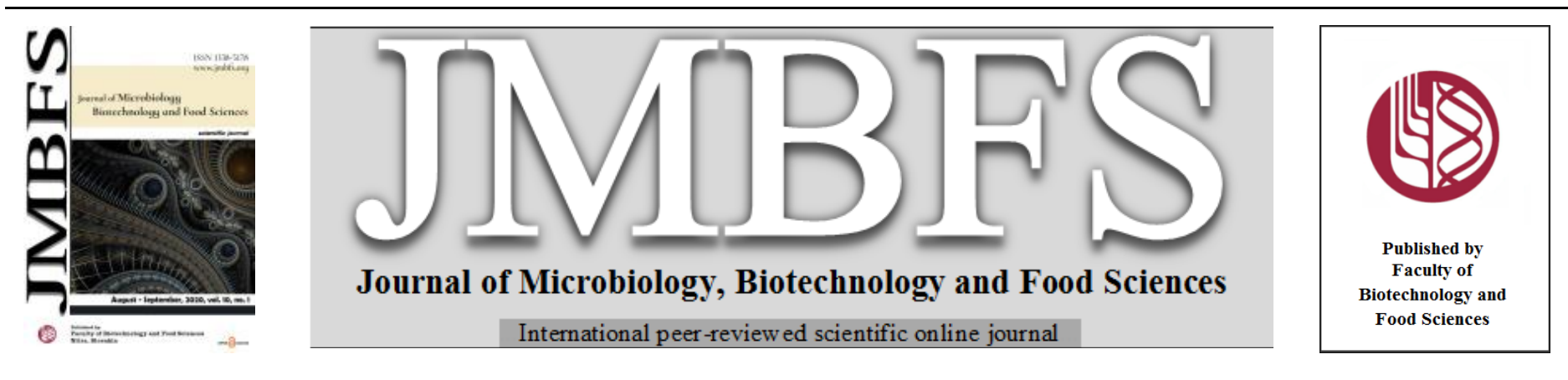

\title{
INTERSPECIFIC HYBRID BETWEEN Saccharomyces mikatae AND Saccharomyces cerevisiae AS AN ALTERNATIVE STRAIN FOR BREAD MAKING
}

\author{
Yuji Oda $^{1,2}$, Subaru Tanizaki ${ }^{1}$, Megumi Yokoyama-Ohtsuka ${ }^{1}$, Hiroaki Sakurai ${ }^{2}$ \\ Address(es): \\ ${ }^{1}$ Obihiro University of Agriculture and Veterinary Medicine, Department of Life and Agricultural Sciences, Obihiro, Hokkaido 080-8555, Japan. \\ ${ }^{2}$ Nippon Beet Sugar Manufacturing Co., Research Center, Obihiro, Hokkaido 080-0831, Japan.
}

*Corresponding author: yujiodahkd@gmail.com

doi: 10.15414/jmbfs.2020.10.1.127-129

\section{ARTICLE INFO}

Received 3. 9.2019

Revised 2. 5. 2020

Accepted 22. 5. 2020

Published 1. 8. 2020

Short communication

open $\partial_{\text {ACCESS }}$

\begin{abstract}
Hybrids of the homothallic diploid Saccharomyces mikatae and heterothallic haploid Saccharomyces cerevisiae isolated from local fruits in Hokkaido and a baking strain, respectively, were constructed by the spore to cell mating method. Interspecific hybridization of the selected strain was confirmed by polymerase chain reaction using species-specific primers, fermentation profiles, and spore formation. The leavening ability of the dough and enzyme activities of the hybrid exhibited intermediate traits of their parental strains. A baking test by the sponge-dough method with a standard formulation of white bread showed that breads produced using the hybrid differed in aroma and taste from those made using a conventional baking strain. Thus, the hybrid may be used to produce baked goods with diverse quality, which may be more acceptable to specific consumers.
\end{abstract}

Keywords: Bread making, Hybrid, Saccharomyces mikatae, Saccharomyces cerevisiae

\section{INTRODUCTION}

Saccharomyces is a teleomorphic ascomycetous genus that generally exhibits vigorous fermentation and includes at least eight species (Alsammar et al., 2019). Saccharomyces cerevisiae is the most widely used species in fermentation processes, including bread making. Yeasts used for bread making leaven dough by producing carbon dioxide through glycolysis and impart desirable qualities to bread based on their fermentation by-products, including alcohols, organic acids, and esters. Domestication of wild yeasts through selection based on rapid dough leavening has resulted in the development of species similar to yeasts used in alcoholic beverage production (Carbonetto et al., 2018). While these selected yeasts may have acquired properties specific to their respective industries, their diversity has declined (Gallone et al., 2018).

Flavor is a complex parameter that determines the quality of baked products (Heitmann et al., 2018). Improvements in bread flavor using different techniques were reported (Martínez-Anaya, 1996, Salim-ur-Rehman et al., 2006), but it is unclear if these methods fully respond to the various and complex demands of consumers. As social structures change including a declining low birth rate and increasing aged population in Japan (Nomura \& Koizumi, 2016), manufacturers in the food industry such as in baking have used differentiated products focused on specific consumers because developing products acceptable to the entire commercial market is difficult (Thakur et al., 2020). One approach for responding to these challenges is to prepare a wider diversity of baking yeast strains.

Saccharomyces yeasts, other than S. cerevisiae, are used in certain fermentation processes; $S$. pastorianus, the natural hybrid of S. eubayanus and S. cerevisiae, is a representative yeast used to produce lager beer (Gallone et al., 2018). Saccharomyces bayanus, S. kudriavzevii, $S$. uvarum, and their hybrids with $S$. cerevisiae are sometimes employed during vinification to improve fermentation characteristics or product quality (Pérez-Torrado et al., 2018). Industrial use of Saccharomyces mikatae, a wild yeast found exclusively in the natural environment in Japan (Naumov et al., 2000), has not been reported. Interspecific hybrids between $S$. mikatae and S. cerevisiae derived from a commercial starter culture altered the metabolite profiles of wine, with respect to the parental wine yeast (Bellon et al., 2013). Another hybrid between S. mikatae and an $S$. cerevisiae ale strain efficiently fermented wort at $12^{\circ} \mathrm{C}$ under lager brewing conditions, and produced more alcohols and esters compared to the parental strains (Nikulin et al., 2018). However, interspecific hybrids between Saccharomyces species for bread making have not been reported.
During a survey of local genetic resources, we found a fermentative yeast strain, identified as $S$. mikatae, which was unsuitable for usual bread making as it exhibited a defect in maltose fermentation. In the present study, this strain of $S$. mikatae was hybridized with haploid $S$. cerevisiae to construct an alternative baking strain for preparing bread with diverse quality, which may be acceptable to specific consumers.

\section{MATERIAL AND METHODS}

\section{Yeast strains}

In this study, the following yeast strains were used (Table 1). The hybrid was constructed by the spore to cell mating method (Garcia Sanchez et al., 2012) Twenty-four spores, dissected from the asci of S. mikatae AK40, formed on SPO agar and were individually paired with single cells of S. cerevisiae $\mathrm{H} 24 \mathrm{U} 1 \mathrm{M}$ using a micromanipulator on YPD agar. After two days, all colonies were transferred onto SD-Glu agar and further incubated for two days. Colonies that appeared on the plate were inoculated onto SD-Mal agar and grown under anaerobic conditions for one day. One well-growing colony was selected from among 18 colonies and isolated as strain DHM15.

Strain AK40 was isolated from a sample of blueberry-like fruits with some leaves attached, which was collected from the Tokachi District of Hokkaido, Japan, in July 2007 after enrichment culture, and identified as S. mikatae based on sequences of the 18S-26S rDNA spacer region (Oda et al., 2010). Strains DHM15, AK40, and H24U1M were deposited as NITE P-02672, NITE P-02673, and NITE P-02508, respectively, in the National Institute of Technology and Evaluation (NITE) Patent Microorganisms Depositary (Kisarazu-shi, Chiba, Japan).

\section{Culture conditions}

Media used for hybridization and related experiments were YPD, SPO (Oda \& Ouchi, 1990), and SD (0.67\% yeast nitrogen base without amino acids, Difco, Detroit, MI, USA) supplemented with either $2 \%$ glucose (SD-Glu) or $2 \%$ maltose (SD-Mal), and thereafter solidified with $2 \%$ agar when necessary. Fermentation of sugar was tested as described previously (Kurtzman et al., 2011). Al cultivations were performed at $30^{\circ} \mathrm{C}$. 
Table 1 Yeast strains used in the present study

\begin{tabular}{|c|c|c|}
\hline Strain & Species & Origin \\
\hline DHM15 & $\begin{array}{l}\text { S. mikatae } \times S \text {. } \\
\text { cerevisiae }\end{array}$ & $\begin{array}{l}\text { Hybrid between strains AK40 and } \\
\text { H24U1M }\end{array}$ \\
\hline AK40 & S. mikatae & Homothallic diploid (wild strain) \\
\hline $\mathrm{H} 24$ & S. cerevisiae & $\begin{array}{l}\text { Haploid (MATa) derived from a baking } \\
\text { strain HP203 }\end{array}$ \\
\hline H24U1M & S. cerevisiae & Uracil-auxotrophic mutant of strain $\mathrm{H} 24$ \\
\hline HP467 & S. cerevisiae & $\begin{array}{l}\text { Conventional baking strain as the } \\
\text { reference }\end{array}$ \\
\hline
\end{tabular}

\section{Leavening ability in dough}

Cells grown in YPS medium containing $2 \% \mathrm{NaCl}$ (Oda et al., 2010) were collected and washed with water to prepare a yeast cake including $33 \%(\mathrm{w} / \mathrm{w})$ cells as dry matter. The dough components, which were $10 \mathrm{~g}$ of bread flour, 5.5 $\mathrm{mL}$ of water or the solution containing $0.5 \mathrm{~g}$ of sucrose plus $0.2 \mathrm{~g}$ of $\mathrm{NaCl}$, and $1.0 \mathrm{~mL}$ of a yeast suspension containing $0.2 \mathrm{~g}$ of the yeast cake, were kept at $30^{\circ} \mathrm{C}$ and mixed quickly by hand for $1 \mathrm{~min}$ after adding the yeast suspension. $\mathrm{CO}_{2}$ evolved from the mixed dough was collected in graduated cylinder over the saturated saline solution and its volume was measured at $30^{\circ} \mathrm{C}$ for $2 \mathrm{~h}$ to determine the leavening ability in dough.

\section{Enzyme assays}

For the $\alpha$-glucosidase assay, $0.05 \mathrm{~mL}$ of the permeabilized cell suspension prepared by vortexing in the presence of chloroform and sodium dodecyl sulfate was added to $1.0 \mathrm{~mL}$ of $50 \mathrm{mM}$ phosphate buffer ( $\mathrm{pH} 6.8$ ) containing $5 \mathrm{mM} p$ nitrophenyl $\alpha$-D-glucopyranoside and incubated at $30^{\circ} \mathrm{C}$ for $30 \mathrm{~min}$. The reaction was stopped by adding $1.0 \mathrm{~mL}$ of $3 \%$ sodium carbonate and released $p$ nitrophenol was determined.

For the invertase assay, a mixture containing $100 \mathrm{mM}$ acetate buffer $(\mathrm{pH} 4.5)$, $150 \mathrm{mM}$ sucrose, and the cell suspension in $0.25 \mathrm{~mL}$ was incubated at $30^{\circ} \mathrm{C}$ for 3 min. The reaction was terminated by mixing $0.25 \mathrm{~mL}$ of 3,5-dinitrosalicylic acid reagent to measure the reducing sugar produced from sucrose.

The specific activities of both enzymes were expressed as nanomoles of products per minute per milligram of cells as dry matter.

\section{Baking test}

Breads were made using the sponge-dough method with a standard formulation of white bread (Oda et al., 2010). These breads were subjected to preliminary sensory evaluation of the rating method by 11 panels made up of students. The panels were trained and frequently perform sensory evaluation of bread. The scales of crumb grain and crumb color are from 0 (poor) to 100 (excellent), that of crumb texture from 0 (hard) to 100 (soft), and those of aroma and taste from 50 (same) to 100 (different). The scores were compared to that of the reference setting at 50. Student's $t$-tests were conducted to detect significant differences between the two baked products.

\section{RESULTS AND DISCUSSION}

\section{Characterization of the hybrid}

Polymerase chain reaction (PCR) was performed to investigate the hybrid DHM15 strain (Figure 1). Specific amplicons corresponding to $S$. mikatae genomic loci (508 base pairs (bp)) were amplified in the DHM15 (lane b) and AK40 (lane d) strains; 1,710-bp amplicons corresponding to S. cerevisiae genomic loci were produced in DHM15 (lane b) and H24 (lane e). Similar patterns were observed when the cells of strain DHM15 were grown in YPD medium 10 times (lane c), suggesting that the genome of strain DHM15 can be stably maintained even under non-selective conditions.

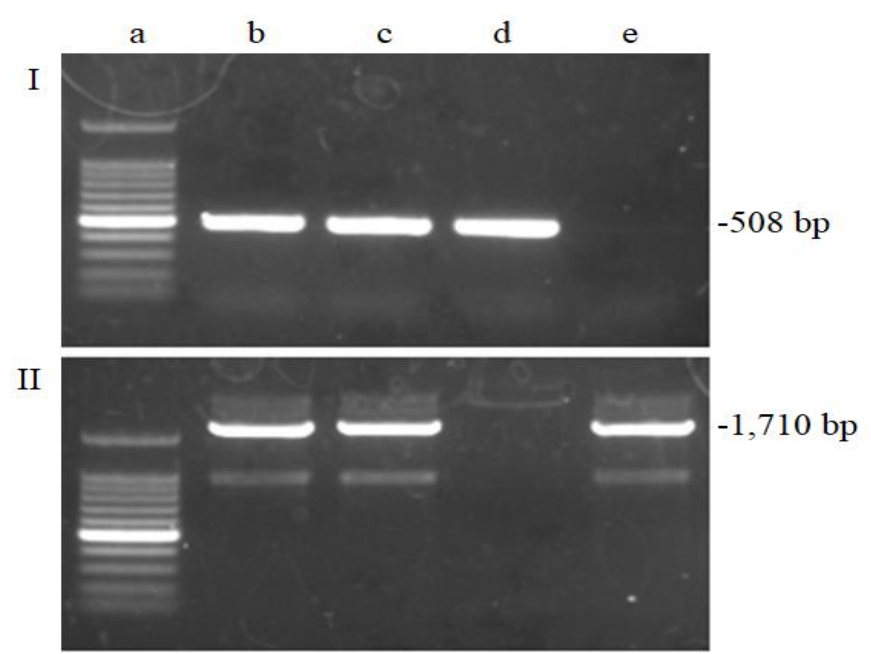

Figure 1 PCR with species-specific primer sets for $S$. mikatae (I) and $S$. cerevisiae (II)

The primer sets used were Smik-F1 ACAAGCAATTGATTTGAGGAAAAG-3') and Smik-R1 (5'CCAGTCTTCTTTGTCAACGTTG-3') for $S$. mikatae (Pengelly \& Wheals, 2013) and YC1f (5'-CTTATGCTTGGAACCTCAAGACA-3') and YC2r (5' AGAAGCAACAACAGCAACAACCCAA-3') for $S$. cerevisiae (Torriani et al., 2004).

Lanes: a, 100-bp DNA ladder; b, DHM15; c, DHM15 after growth (10 times) in YPD medium; d, AK40; e, H24.

Strains DHM15, AK40, and H24 fermented glucose, galactose, sucrose, and raffinose but not lactose. Maltose fermentation was lacking in strain AK40 but observed in strains DHM15 and H24. In contrast, melibiose fermentation by strain AK40, a typical trait of S. mikatae (Naumov et al., 2000), was inherited by strain DHM15 but was not observed in strain H24. Melibiose fermentation ability may be an advantage for a baking strain to completely consume sugars when beet molasses, including raffinose composed of a melibiose moiety, is used as a raw material in commercial propagation (Oda \& Tonomura, 1996). Trehalose was fermented by strains DHM15 and H24 but not by strain AK40.

When cultured on SPO agar for six days, most cells of strain AK40 were converted to asci containing four spores, while those of the haploid strain H24 were not (Figure 2). Strain DHM15 produced spores but much less efficiently than strain AK40. Saccharomyces mikatae has been proposed for use in producing genetically isolated populations of the Saccharomyces sensu stricto complex in Japan, as hybrids between strains NBRC 1815 and NBRC 1816 and four other species do not produce viable spores (Naumov et al., 1995). In the present study, S. mikatae was successfully hybridized with $S$. cerevisiae by the spore to cell mating method, whereas hybrid DHM15 may produce no progeny.
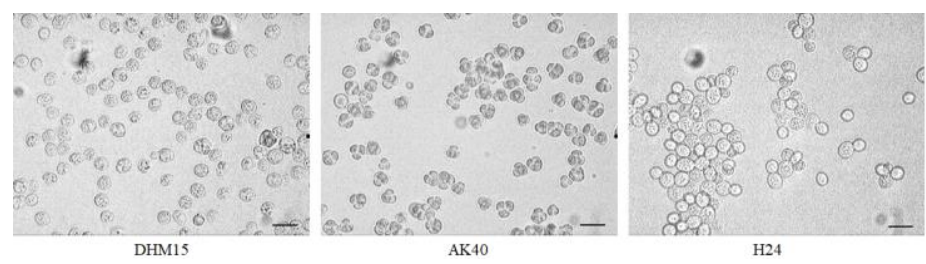

Figure 2 Spore formation of the hybrid and parental strains

Cells of each strain were grown on SPO agar for 6 days at $30^{\circ} \mathrm{C}$. The bar indicates $10 \mu \mathrm{m}$.

\section{Some properties required for baker's yeast}

In a comparison of strain DHB 15 with its parental strains, AK40 and H24, the cell yield and leavening ability of strain AK40 in two doughs were increased by hybridization (Table 2 ). The basal activity of $\alpha$-glucosidase produced by strain AK40 showed the lowest leavening ability in the dough without added sugar, which was explained by a defect in the fermentation of maltose, the principal fermentable sugar derived from starch via the action of amylases. In contrast strain AK40 synthesized enough invertase to hydrolyze sucrose. Hybrid DHM15 showed intermediate properties of the parental strains to reach sufficient levels compared to those of the baking strain HP467. These results suggest that the hybrid can be applied in bread making by the sponge-dough method. 
Table 2 Properties required for baker's yeast

\begin{tabular}{|c|c|c|c|c|c|}
\hline \multirow{2}{*}{ Strain } & \multirow{2}{*}{$\begin{array}{l}\text { Cell yield } \\
\text { (g as dry matter } \\
/ 60 \mathrm{~mL} \text { of medium) }\end{array}$} & \multicolumn{2}{|c|}{$\begin{array}{l}\text { Leavening ability in dough } \\
\text { (mLof } \mathrm{CO}_{2} / 2 \mathrm{~h} / 10 \mathrm{~g} \text { flour) }\end{array}$} & \multicolumn{2}{|c|}{$\begin{array}{l}\text { Enzyme activity } \\
(\mathrm{nmol} / \mathrm{min} / \mathrm{mg} \text { cells as dry matter) }\end{array}$} \\
\hline & & $\begin{array}{l}\text { Without } \\
\text { sugar }\end{array}$ & $\begin{array}{l}+5 \% \text { sucrose } \\
+2 \% \mathrm{NaCl}\end{array}$ & $\alpha$-Glucosidase & Invertase \\
\hline DHM15 & $0.749 \pm 0.017$ & $48.5 \pm 3.8$ & $48.0 \pm 4.1$ & $635 \pm 161$ & $1,280 \pm 40$ \\
\hline AK40 & $0.631 \pm 0.013$ & $17.1 \pm 0.9$ & $41.1 \pm 3.4$ & $13 \pm 4$ & $3,620 \pm 80$ \\
\hline $\mathrm{H} 24$ & $0.561 \pm 0.002$ & $55.6 \pm 1.1$ & $51.7 \pm 4.1$ & $1,330 \pm 230$ & $126 \pm 3$ \\
\hline HP467 & $0.711 \pm 0.018$ & $32.0 \pm 2.6$ & $48.8 \pm 3.3$ & $84 \pm 31$ & $400 \pm 23$ \\
\hline
\end{tabular}

These experiments were performed three times independently and the obtained data are shown as the average values \pm standard deviations.

\section{Baking performance}

The specific volume of bread produced using hybrid DHM15 was lower than that of the bread produced using strain HP467. A value higher than $5.0 \mathrm{~mL} / \mathrm{g}$ is acceptable in the market. In the sponge-dough method, the DHM15 hybrid rapidly fermented the sponge in $4 \mathrm{~h}$, and may not have evolved $\mathrm{CO}_{2}$ rapidly after remixing with the remaining materials, including sugar and other ingredients, as determined from the leavening ability of dough with $5 \%$ sucrose and $2 \% \mathrm{NaCl}$
(Table 2). Preliminary sensory evaluation of these breads revealed slight differences in the quality of the crumb grain, texture, and crumb color (Table 3 ). The scores for the differences in aroma and taste for hybrid DHM15 were higher than those for strain HP467, and a significant difference in taste was found These results indicate that the bread made using hybrid DHM15 had distinct qualities.

$\underline{\text { Table } 3 \text { Qualities of baked breads by the sponge-dough method }}$

\begin{tabular}{cllllll}
\hline \multirow{2}{*}{ Strain } & \multirow{2}{*}{$\begin{array}{l}\text { Specific volume } \\
(\mathrm{mL} / \mathrm{g})^{\mathrm{a}}\end{array}$} & \multicolumn{2}{l}{ Crumb evaluation $(-)^{\mathrm{b}}$} & & & \\
\cline { 2 - 6 } & & Crumb grain & Texture & Color & Aroma & Taste \\
\hline DHM15 & $5.30 \pm 0.18$ & $46.3 \pm 13.4$ & $49.8 \pm 8.2$ & $45.1 \pm 7.6$ & $55.0 \pm 11.5$ & $58.5 \pm 8.3^{* *}$ \\
HP467 & $6.01 \pm 0.11^{* *}$ & $50.0 \pm 0.0$ & $50.0 \pm 0.0$ & $50.0 \pm 0.0$ & $50.0 \pm 0.0$ & $50.0 \pm 0.0$ \\
\hline${ }^{\mathrm{a}} n=4 ;{ }^{\mathrm{b}} n=11, * * P<0.01$ & & & & &
\end{tabular}

\section{CONCLUSION}

The hybrid between $S$. mikatae and $S$. cerevisiae may be used to produce baked goods with diverse quality, which may be acceptable to specific consumers Differences in the quality of fermented products should be investigated by analyzing their soluble and volatile compounds.

Acknowledgments: We would like to thank Hiroaki Yamauchi for his helpful advice on the baking experiments and Editage (www.editage.jp) for English language editing.

\section{REFERENCES}

Alsammar, H. F., Naseeb, S., Brancia, L. B., Gilman, R. T., Wang, P. \& Delneri, D. (2019). Targeted metagenomics approach to capture the biodiversity of Saccharomyces genus in wild environments. Environmental Microbiology Reports, 11(2), 206-214. https://doi.org/10.1111/1758-2229.12724

Bellon, J. R., Schmid, F., Capone, D. L., Dunn, B. L. \& Chambers, P. J. (2013) Introducing a new breed of wine yeast: interspecific hybridisation between a commercial Saccharomyces cerevisiae wine yeast and Saccharomyces mikatae. PLoS One, 8(4), e62053. https://doi.org/10.1371/journal.pone.0062053

Carbonetto, B., Ramsayer, J., Nidelet, T., Legrand, J. \& Sicard, D. (2018). Bakery yeasts, a new model for studies in ecology and evolution. Yeast, 35(11) 591-603. https://doi.org/10.1002/yea.3350

Gallone, B., Mertens, S., Gordon, J. L., Maere, S., Verstrepen, K. J. \& Steensels, J. (2018). Origins, evolution, domestication and diversity of Saccharomyces beer yeasts. Current Opinion in Biotechnology, 49, 148-155. https://doi.org/10.1016/j.copbio.2017.08.005

Garcia Sanchez, R., Solodovnikova, N. \& Wendland, J. (2012). Breeding of lager yeast with Saccharomyces cerevisiae improves stress resistance and fermentation performance. Yeast, 29(8), 343-355. https://doi.org/10.1002/yea.2914

Heitmann, M., Zannini, E. \& Arendt, E. (2018). Impact of Saccharomyces cerevisiae metabolites produced during fermentation on bread quality parameters: A review. Critical Reviews in Food Science and Nutrition, 58(7), 1152-1164. https://doi.org/10.1080/10408398.2016.1244153

Kurtzman, C. P., Fell, J. W., Boekhout, T. \& Robert, V. (2011). Methods for isolation, phenotypic characterization and maintenance of yeasts. In:Kurtzman, C. P., Fell, J. W. \& Boekhout, T. (Eds), The Yeasts, a Taxonomic Study, Vol. 1 Elsevier, Amsterdam, pp. 87-110. https://doi.org/10.1016/B978-0-444-52149. $\underline{1.00007-0}$

Martínez-Anaya, M. A. (1996). Enzymes and bread flavor. Journal of Agricultural and Food Chemistry, 44(9), 2469-2480. https://doi.org/10.1021/jif960020d

Naumov, G. I., James, S. A., Naumova, E. S., Louis, E. J. \& Roberts, I. N. (2000). Three new species in the Saccharomyces sensu stricto complex: Saccharomyces cariocanus, Saccharomyces kudriavzevii and Saccharomyces mikatae. International Journal of Systematic and Evolutionay Microbiology, 50(5), 1931-1942. https://doi.org/10.1099/00207713-50-5-1931

Naumov, G. I., Naumova, E. S. \& Louis, E. J. (1995). Two new genetically isolated populations of the Saccharomyces sensu stricto complex from Japan.
Journal of General and Applied Microbiology, 41(6), 499-505. https://doi.org/10.2323/jgam.41.499

Nikulin, J., Krogerus, K. \& Gibson, B. (2018). Alternative Saccharomyces interspecies hybrid combinations and their potential for low-temperature wort fermentation. Yeast, 35(1), 113-127. https://doi.org/10.1002/yea.3246

Nomura, K. \& Koizumi, A. (2016). Strategy against aging society with declining birthrate in Japan. Industrial Health, 54(6), 477-479. https://doi.org/10.2486/indhealth.54-477

Oda, Y., Mikumo, D., Tajima, K. \& Yamauchi, H. (2010). Characterization of an alternative baking strain of Saccharomyces cerevisiae isolated from fermented cherry fruits by the analysis of SUC2 gene. Food Science and Technology Research, 16(1), 45-50. https://doi.org/10.3136/fstr.16.45

Oda, Y. \& Ouchi, K. (1990). Hybridization of Bakers' yeast by the rare-mating method to improve leavening ability in dough. Enzyme and Microbial Technology, 12(12), 989-993. https://doi.org/10.1016/0141-0229(90)90122-7

Oda, Y. \& Tonomura, K. (1996). $\alpha$-Galactosidase from the yeast Torulaspora delbrueckii IFO 1255. Journal of Applied Bacteriology, 80(2), 203-208. https://doi.org/10.1111/j.1365-2672.1996.tb03211.x

Pengelly, R. J. \& Wheals, A. E. (2013). Rapid identification of Saccharomyces eubayanus and its hybrids. FEMS Yeast Research, 13(2), 156-161. https://doi.org/10.1111/1567-1364.12018

Pérez-Torrado, R., Barrio, E. \& Querol, A. (2018). Alternative yeasts for winemaking: Saccharomyces non-cerevisiae and its hybrids. Critical Reviews in Food Science and Nutrition, 58(11), 1780-1790. https://doi.org/10.1080/10408398.2017.1285751

Salim-ur-Rehman, Paterson, A. \& Piggott, J. R. (2006). Flavour in sourdough breads: a review. Trends in Food Science and Technology, 17(10), 557-566 https://doi.org/10.1016/j.tifs.2006.03.006

Thakur, M., Chandel, A. K., Kumar, S. \& Verma, M. L. (2020). Biotechnological production of phytosteviosides and their potential applications. In:Verma, M. L. \& Chandel, A. K. (Eds), Biotechnological Production of Bioactive Compounds, Elsevier, Amsterdam, pp. 139-164. https://doi.org/10.1016/B978-0-444-643230.00005-9

Torriani, S., Zapparoli, G., Malacrino, P., Suzzi, G. \& Dellaglio, F. (2004). Rapid identification and differentiation of Saccharomyces cerevisiae, Saccharomyces bayanus and their hybrids by multiplex PCR. Letters in Applied Microbiology, 38(3), 239-244. https://doi.org/10.1111/j.1472-765X.2004.01468.x 